\title{
Nonerosive Arthritis
}

National Cancer Institute

\section{Source}

National Cancer Institute. Nonerosive Arthritis. NCI Thesaurus. Code C119023.

An inflammation of one or more joints, without loss of articular cartilage or destruction of subchondral bone. 